\title{
CORRESPOINDENNCE.
}

ON THE SUPPOSED PECTORAL LIMB IN COCCOSTEUS DECIPIENS.

Srr,-Permit me a few words in reply to Prof. v. Koenen's most courteous remonstrance concerning the supposed pectoral limb in Coccosteus.

Although I did indeed suggest that Prof. v. Koenen may have mistaken the outer margin of the interlateral plate in his C. Bickensis for a pectoral spine, I did so without dogmatism; and when I have the opportunity of examining the German specimens, I shall do so with a mind perfectly open to conviction.

But I stand firm as regards the position which I have taken up as regards the absence of any such "Ruderorgan" in Coccosteus decipiens, the type of the genus; and I do not think that the argument upon which Prof. v. Koenen bases his expectations of its ultimate discovery in this species, carries any weight whatever. When we take into account the position in the head of the sclerotic ring, its delicacy, and the manner in which the Scotch specimens are crushed, it is by no means astonishing that this structure should be so rarely observable in Coccosteus decipiens. Far otherwise would he the case with a pectoral limb, were such a thing present,--for it is simply incredible that a long stout promirent external appendage, like the "Ruderorgan" in Prof. v. Koenen's restored figure, should have escaped preservation in the hundreds and hundreds of specimens of Scotch Coccosteus, which are to be found in the nuseums of this country, many of which are absolutely entire from the tip of the snout to the point of the tail.

I cannot therefore share Prof. v. Koenen's expectations as to the future discovery of a pectoral limb in Coccosteus decipiens, and consequently must still maintain that if such a limb is really present in C. Bickensis, v. Koenen, that species must be removed to a new genus.

7 th April, 1890.

R. H. Traquair.

\section{MR. MELLARD READE ON THE PHYSIOGRAPHY OF THE LOWER TRIAS.}

SIR,-So kindly is the tone of Mr. Mellard Reade's reply to my criticisms on his explanation of the Pbysiography of the Lower Trias that it is not without regret that $I$ am compelled to observe that in my opinion he has failed to meet them. His reply, in short, as it seems to me, errs in excess and in defect. In excess, for these reasons :

(1) I do not "misconceive the facts in speaking of the Bunter generally as a "conglomerate." Mr. Mellard Reade has misunderstood my words by isolating my last paper from all that I have previously written. I have touched upon the anomaly of the Lancashire Bunter (of what I know something) twice at least (GEoL. MAG. Dec. II. Vol. X. p. 204: Address to Sect. C, British Association, Birmingham, 1886). I did not again mention it, because I had nothing to add to my previous remarks. In reading the proof the 